\title{
Medievalista
}

Online

13 | 2013

Número 13

\section{A «Crónica de Portugal de 1419»: fontes, estratégias e posteridade}

Tese de Doutoramento em Literaturas e Culturas Românicas apresentada à Faculdade de Letras da Universidade do Porto, Janeiro 2011. Orientação do Professor Doutor José Carlos Ribeiro Miranda

\section{Filipe Alves Moreira}

\section{(2) OpenEdition}

12 Journals

\section{Edição electrónica}

URL: http://journals.openedition.org/medievalista/608

DOI: 10.4000/medievalista.608

ISSN: 1646-740X

Editora

Instituto de Estudos Medievais - FCSH-UNL

Refêrencia eletrónica

Filipe Alves Moreira, «A «Crónica de Portugal de 1419»: fontes, estratégias e posteridade »,

Medievalista [Online], 13 | 2013, posto online no dia 19 fevereiro 2014, consultado o 22 setembro 2020.

URL : http://journals.openedition.org/medievalista/608; DOI : https://doi.org/10.4000/medievalista. 608

\section{(c) (7) (8)}

Mediavalista está licenciado com uma Licença Creative Commons - Atribuição-NãoComercial 4.0 Internacional 
Título: Apresentação de Tese

A «Crónica de Portugal de 1419» : fontes, estratégias e posteridade

Tese de Doutoramento em Literaturas e Culturas Românicas apresentada à Faculdade de Letras

da Universidade do Porto, Janeiro 2011. Orientação do Professor Doutor José Carlos Ribeiro Miranda.

Autor(es): Filipe Alves Moreira

Enquadramento Institucional: Instituto de Filosofia/Universidade do Porto, Portugal

Contacto: filipe_24lit@aeiou.pt

Fonte: Medievalista [Em linha]. №13, (Janeiro - Junho 2013). Dir. José Mattoso. Lisboa: IEM.

Disponível em: http://www2.fcsh.unl.pt/iem/medievalista/

ISSN: $1646-740 \mathrm{X}$

\section{Apresentação de Tese}

\section{A «Crónica de Portugal de 1419»: fontes, estratégias e posteridade}

Tese de Doutoramento em Literaturas e Culturas Românicas apresentada à Faculdade de Letras da Universidade do Porto, Janeiro 2011. Orientação do Professor Doutor José Carlos Ribeiro Miranda.

Filipe Alves Moreira 
Setenta anos decorridos desde o (re)descobrimento da chamada Crónica de Portugal de 1419, é possível descortinar duas grandes fases nos estudos a ela dedicados. A fase inicial, grosso modo correspondente às décadas de 40 e de 50 do século passado, teve como preocupação fundamental - e em muitos casos exclusiva, ou quase - determinar a autoria desta crónica, e mais concretamente determinar se, sim ou não, será ela a famosa primeira parte das Crónicas dos reis de Portugal redigidas por Fernão Lopes. A leitura das sínteses/comentários bibliográficos elaborados por Magalhães Basto (1960) e por Giuliano Macchi (1963) evidencia claramente essa preocupação maior. A realização de estudos globais sobre esta crónica foi, é certo, uma necessidade várias vezes sentida e proclamada ao longo desta época, mas apenas o já referido Magalhães Basto chegou a prometer um volume em que se ocuparia das «razões do interesse da [Crónica de 1419], [d]o estudo da determinação das suas fontes certas ou prováveis, [das] relações com outras crónicas, [do] exame do problema da autoria, etc.». O prometido volume jamais passaria das intenções, muito embora Magalhães Basto tenha podido realizar parte do plano inicialmente traçado, através de comunicações a congressos, artigos de jornais ou palestras várias que, já no fim da vida, foi ainda a tempo de reunir em cómodo e utilíssimo volume.

Pertencem também a esta fase inicial, e como seria de esperar, as edições dos dois manuscritos principais da Crónica de 1419 (o 886 da Biblioteca Pública do Porto e o M-VIII-15 [olim 965] da Casa Cadaval) - edições todavia efetuadas a partir de diferentes critérios, mais claros e unívocos no caso da edição de Magalhães Basto; mais difusos no caso da edição de Silva Tarouca (o que, diga-se de passagem, constituiu ou constitui fonte de dificuldades várias, dado o muito difícil acesso direto ao fundo de manuscritos da Casa Cadaval). Muito menos presentes nesta fase estiveram estudos de outro tipo, apesar de não menos fundamentais. Bastará pensarmos na identificação das fontes da Crónica, questão que, nestas épocas, apenas parece ter interessado Magalhães Basto, Lindley Cintra ou, e mais pontualmente, Silva Tarouca e Diego Catalán.

Após o quase deserto que caracterizou as décadas de 60, 70 e 80 do século passado, só nos anos 90 assistimos a um renovado interesse no estudo desta crónica. Terá coincidido este renovado interesse com uma espécie de boom dos estudos literários sobre época medieval, em Portugal. Arrefecida deveras a polémica em torno da autoria da crónica (em alguns casos, afirmando-se sem problematização a autoria de Fernão 
Lopes; noutros casos, defendendo-se uma atitude de reserva todavia muito próxima da recusa dessa autoria), orientou-se a investigação dessa década e da década seguinte, segundo parece, para análises mais ou menos detalhadas de determinado episódio, trecho ou relato de reinado da crónica, e já não para os estudos globais que, pelo menos em projeto, estiveram na mente de alguns estudiosos de anteriores gerações, maxime Magalhães Basto. É de salientar que, nesta segunda fase, a Crónica de 1419 foi muito raramente objeto de análises especificamente a ela dedicadas. A regra, pelo contrário, foi mencioná-la a propósito de qualquer outro assunto. Tipicamente, tomava-se por objeto de estudo a construção das imagens de determinada figura ou evento histórico ao longo dos tempos (D. Afonso Henriques, o milagre de Ourique, etc., mas sobretudo estes), e a Crónica de 1419 era encarada como um de vários textos trabalhados no âmbito da análise dessas imagens. Não será difícil adivinhar as vantagens e as desvantagens decorrentes deste tipo de abordagem. De entre as exceções, deverá porventura salientar-se a tese de doutoramento de Esther Alfonso Pinto, apresentada à Universidade do Texas em finais da década de 90, e especificamente dedicada ao estudo do reinado de D. Afonso I tal qual relatado pela Crónica de 1419 (sendo esta, aliás, e tanto quanto julgo saber, a segunda dissertação académica especificamente dedicada e esta crónica, trinta anos depois da tese de licenciatura de José Luis Porfírio apresentada à Faculdade de Letras da Universidade de Lisboa; anos depois, também Albano Figueiredo trataria da Crónica de 1419 na sua tese de Doutoramento). Exceção no que respeita a tomar-se a Crónica de 1419 como objeto específico de estudo, que não quanto a análises de tipo global. Outro mérito teve a tese de Alfonso-Pinto, e foi o de chamar a atenção para as possíveis e possivelmente estreitas relações existentes entre a Crónica de 1419 e a produção historiográfica ou literária castelhana, embora nem todas as suas conclusões me pareçam igualmente bem fundamentadas. Precisamente o alheamento da crítica nacional face às relações, intertextuais ou de outro tipo, entre a historiografia portuguesa medieval e a historiografia ibérica da mesma época afigura-se-me uma das mais visíveis insuficiências da investigação post-Lindley Cintra nesta área (com a exceção das três crónicas seguramente da autoria de Fernão Lopes, cujas relações com a obra de Ayala foram sendo estudadas de forma quase continuada). Apenas a partir de finais dos anos 90 esta insuficiência começou verdadeiramente a ser colmatada - e não digamos nada de análises das possíveis relações entre a historiografia portuguesa medieval e a historiografia de outras zonas geográficas e culturais que não a Península 
Ibérica, ainda hoje virtualmente não existentes, segundo já Teresa Amado foi notando. O acontecimento da década de 90, no que ao estudo da Crónica de 1419 diz respeito, foi porém a modelar edição crítica de Adelino de Almeida Calado, que, entre outros méritos, possibilitou uma mais clara perceção dos limites do texto de 1419. Com efeito, a opção de Silva Tarouca, de editar o manuscrito da Casa Cadaval na íntegra, incluindo (mas, é justo dizê-lo, em itálico) os capítulos pertencentes à Crónica de D. Afonso Henriques da autoria de Duarte Galvão e às Crónicas de D. Dinis e de D. Afonso IV da autoria de Rui de Pina, foi originando equívocos vários a respeito do efetivo conteúdo da crónica quatrocentista. Tais equívocos tornaram-se de todo injustificáveis com a edição Calado.

O que aí fica dito ajudará a compreender a oportunidade da dissertação aqui apresentada. Pareceu-me, assim, necessário encarar a Crónica de 1419 como objeto específico de estudo, e realizar a análise global cuja necessidade vinha sendo sentida praticamente desde que se descobriram os apógrafos principais desta obra. Não pretendi, obviamente, retomar os parâmetros conceptuais e metodológicos próprios da investigação de meados do século XX, mas sim - sem esquecer o seu contributo acrescentar-lhe as aportações da crítica mais recente e as minhas próprias propostas, com vista a uma leitura global e articulada da Crónica de 1419. Assumi, desde o início, a necessidade de ter em conta, simultaneamente, o texto estabelecido por Adelino Calado e o texto de cada um dos manuscritos subsistentes (creio inatacável a conclusão a que chega Calado quanto ao facto de o manuscrito do Porto e o manuscrito da Casa Cadaval não terem um «antecessor comum em qualquer ponto da sua linha genealógica exceto o próprio original», constituindo cada um deles, assim, e por si só, ramos diferentes da transmissão textual, independentemente do número de cópias que tenham existido antes deles). E estabeleci como objetivo a análise dos processos de escrita da Crónica e suas implicações discursivas. Julguei também importante dedicar o mesmo tipo de atenção à receção da Crónica de 1419 por parte de historiógrafos portugueses e espanhóis dos séculos XV e XVI, tema praticamente inexplorado e, segundo me parecia e adiante procurarei justificar, do maior interesse. Do primeiro destes dois grandes objetivos ocupa-se a parte II da dissertação, sendo a parte III dedicada ao segundo. A parte I descreve os manuscritos atualmente conhecidos da Crónica de 1419, tendo em atenção os respetivos conteúdos, trajetos e relações estemáticas e incluindo dois 
manuscritos com cópias fragmentárias (reinado de D. Sancho II) que não tinham ainda sido identificados. Refiro-me ao «Livro 20 do Convento de Santa Clara de Vila do Conde» da Torre do Tombo (cuja cópia fragmentária da Crónica de 1419 foi identificada por mim mesmo e pelo Prof. Arthur Lee-Francis Askins em investigações para o projeto BITAGAP) e ao COD. 11248 da Biblioteca Nacional (cuja cópia fragmentária da Crónica de 1419 foi identificada por mim mesmo).

Justamente a identificação destes dois novos testemunhos (parciais) da Crónica de 1419 será um dos principais achados da investigação conducente à elaboração da presente dissertação. Magalhães Basto tinha já localizado, nos anos 40, um manuscrito quinhentista da Biblioteca Pública Municipal do Porto que contém um conjunto de crónicas dos reis de Portugal, desde D. Afonso Henriques até D. Afonso IV, e em que o reinado de D. Sancho II não corresponde ao da respetiva Crónica da autoria de Rui de Pina, mas sim ao relato da Crónica de 1419. Este manuscrito tem sido, erroneamente a meu ver, ignorado (Adelino Calado nem mesmo o menciona na sua edição). A localização de mais dois manuscritos quinhentistas em que se verifica a ausência da Crónica de D. Sancho II de Rui de Pina e sua «substituição» pelo relato do respetivo reinado da Crónica de 1419 mostra que o já mencionado manuscrito da Biblioteca Publica do Porto não é caso isolado, além de ser um indício de que a Crónica de 1419 teve uma difusão maior do que seria de pensar (mais à frente retomarei esta questão). A colação de todos os testemunhos da Crónica de 1419 conhecidos revela que as cópias fragmentárias (designo assim as três cópias do reinado de D. Sancho II; claro que, em rigor, também os manuscritos do Porto $(\mathrm{P})$ e de Cadaval (C) são fragmentários) estão mais próximas de $\mathrm{P}$ do que de $\mathrm{C}$, sendo possível agrupá-los numa família. A cópia fragmentária da Biblioteca Nacional (que designei por «L») é, sem dúvida, um codex descriptus, pois copia o testemunho fragmentário do Porto ( $\mathrm{Pf} »$ na minha designação). Mas a cópia fragmentária da Torre do Tombo (que designei por «T») é independente de Pf e de L. Nenhum destes três testemunhos copia P (nem, como se viu, C), e T, além de mais antigo que $\mathrm{P}$, parece mesmo preservar melhor a lição do original em várias ocasiões. É todavia possível, e desejável, aprofundar o estudo destas questões. Eu mesmo espero poder apresentar em ocasião oportuna certas correções e melhoramentos em relação à descrição do testemunho L que incluo na dissertação. Sobre as razões da «substituição» da Crónica de D. Sancho II pela Crónica de 1419 nestes testemunhos 
(problema que pertence já à receção destas obras), várias hipóteses poderão levantar-se. O copista/compilador de Pf declara expressamente ter copiado o relato do reinado de D. Sancho II porque o considerava «velho»e por isso «saboroso», apesar de redigido num português «feo». O copista de T nada diz sobre o assunto. O estudo combinado da tradição manuscrita da Crónica de 1419 e da Crónica de D. Sancho II de Rui de Pina leva-me, porém, a considerar como extremamente plausível que nem o copista de Pf, nem o de T (ou o de um seu hipotético modelo) tiveram acesso à Crónica de D. Sancho II, de Pina. Como veremos, isso mesmo aconteceu com pelo menos um outro compilador quinhentista.

Abordo também na Parte I da dissertação a questão da autoria da Crónica de 1419. Continuo a considerar como mais plausível a autoria efetiva de Fernão Lopes, não me parecendo conclusivos os argumentos que vêm sendo apresentados em sentido contrário. A questão será, porém, racionalmente irresolúvel. Não me parece, por outro lado, producente minimizar, ou mesmo ignorar, como por vezes se faz, a circunstância de o próprio texto da Crónica incluir uma indicação explícita a propósito das suas condições de produção. Tanto $\mathrm{C}$, como $\mathrm{P}$ (manuscritos que, recorde-se, derivam independentemente do original) declaram expressamente, durante o relato do reinado de D. Afonso I, que «Nós, o Infante, fizemos esta crónica». «Nós, o Infante», ou seja, D. Duarte (não tem razão Adelino Calado quando pretende que a referida indicação é ambígua ou inconclusiva) quis, assim, deixar o seu nome associado à feitura desta crónica. Ela deverá, pois, entender-se, no que às suas condições de produção diz respeito, como uma peça mais do projeto de legitimação e glorificação da dinastia de Avis e da coroa portuguesa impulsionado, em boa medida, por aquele príncipe (compreender-se-á assim, por exemplo, o alcance da alegação presente no capítulo inicial da Crónica, segundo a qual de D. Henrique e D. Teresa «vierão todos os reis de Portugal que forão atee a composição desta cronica»). E isso será mais importante do que a identificação do indivíduo que efetiva e materialmente redigiu o que hoje conhecemos pela designação de Crónica de Portugal de 1419.

A parte II da dissertação ocupa-se, segundo já indiquei, da análise dos processos de construção da Crónica de 1419 e suas implicações. Como tipicamente sucede com a historiografia medieval, também esta Crónica é um texto feito a partir de textos, é, evocando uma frase célebre nos estudos literários, um «mosaico de citações». Isso torna 
pertinente uma análise alicerçada no estudo das fontes conhecidas (e das versões conhecidas das fontes conhecidas...) da Crónica e no modo como elas foram usadas pelo seu redator, de forma a possibilitar a apreensão de mecanismos produtores de sentido.

O cronista de 1419 aproveitou praticamente todas as fontes historiográficas (ou parahistoriográficas) portuguesas, em Latim e em vulgar, anteriores ao século XV hoje subsistentes. Uma interessante - e importante - exceção são os Livros de Linhagens medievais, que verdadeiramente não sabemos se foram desconhecidos (parece haver um silêncio total sobre os velhos nobiliários ao longo do século XV) ou deliberadamente rejeitados pelo cronista.

O percurso lógico seguido na elaboração da Crónica de 1419 foi o seguinte: adoção da história dos reis de Portugal constante da primeira redação da Crónica de 1344 como estruturador geral do discurso; inserção de passagens provenientes das restantes fontes de acordo com dois grandes critérios, o cronológico e o temático, com predomínio do primeiro; adição de elementos funcionalmente destinados a clarificar, precisar ou harmonizar o texto, tais como glosas e comentários que, adicionalmente, sinalizam a emergência de uma razão formalizante que assume a responsabilidade do que vai sendo enunciado; elaboração de uma macroestrutura, de acordo com a qual os episódios foram agrupados em unidades coincidentes com os sucessivos reinados, os quais revelam, assim, certa autonomia que não chega, porém, a pôr em causa a unidade da obra.

É possível, por outro lado, dividir e hierarquizar as fontes da Crónica de 1419 hoje conhecidas, de acordo com a função que assumem na estruturação do discurso, em fonte estrutural primária, fontes estruturais suplementares, e fontes secundárias. Fonte estrutural primaria é o texto a partir do qual se organizou toda a Crónica, cabendo esse papel, como se viu, à Crónica de 1344; fontes estruturais suplementares são os textos que cumprem a mesma função a respeito de determinado episódio (por exemplo o $D e$ Expugnatione Scalabis para a conquista de Santarém no reinado de D. Afonso I, ou o Carmen Gosuini para a conquista de Alcácer do Sal no de D. Afonso II); fontes secundárias são aquelas a que o redator recorre unicamente com o propósito de adicionar informação à fonte estrutural primaria e/ou às fontes estruturais suplementares. A esta hierarquização narrativa não corresponde, porém, uma 
hierarquização semântica (ou semântico-ideológica). Parece, com efeito, poder dizer-se, quanto a este aspeto, que o redator da Crónica de 1419 concede primazia às fontes documentais e a um conjunto de textos dedicados à celebração de conquistas cristãs ou de lutas contra os muçulmanos (por exemplo os já mencionados De Expugnatione Scalabis e Carmen Gosuini), dando geralmente preferência às suas versões sobre as dos restantes textos em caso de contradições entre eles. A autoridade máxima é, contudo, o próprio redator (ou a tal «razão formalizante»), que explicita ou implicitamente sujeita todas as fontes a crítica, omitindo, deslocando, justapondo, reescrevendo ou comentando quanto e quando lhe apraz.

Várias são, com efeito, as modificações introduzidas pelo redator quatrocentista no texto herdado das suas fontes, e várias parecem ser as razões para isso, desde a necessidade de adaptação de textos de diferentes tipologias às convenções próprias do discurso historiográfico; às exigências de verosimilhança e de coerência narrativa; ou a motivações que poderíamos classificar de ideológicas, visíveis estas na conceptualização do poder real e no destaque concedido à atuação dos sucessivos monarcas, sobretudo, mas também das ordens militares e da cidade de Lisboa (os seus habitantes, os seus bispos, o seu padroeiro). Um caso que permite apreender de forma especialmente interessante os métodos de trabalho do redator quatrocentista é o que respeita às guerras «civis» que opuseram D. Dinis e o Infante herdeiro, no final do reinado. Temos aqui excecionalmente acesso a todas as fontes manejadas pelo cronista, tanto narrativas (a Crónica de 1344 e a Vida da Rainha Isabel), como documentais (sobretudo os sucessivos manifestos emitidos pelo Rei contra o Infante), fontes essas que apresentam, cada qual, a sua própria versão dos acontecimentos, de acordo com o posicionamento dos respetivos autores. Podemos por isso ir desmontando a forma como o cronista do século XV foi capaz de construir, a partir destas bases, um relato nitidamente destinado a justificar as ações do monarca e a responsabilizar o Infante por tudo o que de negativo o confronto trouxe, e as estratégias que para isso seguiu, incluindo a redação de uma espécie de prólogo do relato da guerra civil que constitui um dos momentos mais claros de irrupção da voz do autor no interior da narração.

A III parte da dissertação dedica-se, como acima digo, ao estudo da receção da Crónica de 1419. O tema estava virtualmente por explorar, apesar da sua importância. Por esta via poderemos, com efeito, tentar caracterizar o tipo de leituras de que a Crónica de 
1419 foi alvo; os públicos a que se dirigiria ou a que acabou por estar associada; os circuitos por que as suas cópias passaram; as manipulações a que foi sujeita; o interesse ou desinteresse que suscitou, etc. Além disso, quando uma obra chegou ate nós a partir de uma tradição manuscrita e/ou impressa de alguma maneira deficitária (devido a copias lacunares, contaminadas, deturpadas, mutiladas ou por qualquer outra razão imperfeitas), o estudo de textos que denotam tê-la conhecido e aproveitado poderá ajudar a circunscrever melhor, se não a hipotética pureza do texto original, pelo menos as linhas gerais do seu conteúdo e estrutura. Um bom exemplo da importância deste tipo de estudo são os sucessivos trabalhos que Diego Catalán dedicou à por ele mesmo descoberta e designada «Gran Crónica de Alfonso XI», texto conservado em manuscritos tardios e incompletos, mas que foi resumido ou aproveitado por diversos autores. No caso específico da Crónica de 1419, e tendo em conta a sua tradição textual, este pressuposto poderá revelar-se especialmente operativo para os relatos dos reinados de D. Dinis e de D. Afonso IV, muito lacunarmente transmitidos por apenas um dos códices (C) que até nós chegaram. E isto porque não é impossível (e diria até ser provável) que alguém tenha chegado a conhecer e aproveitar uma cópia mais completa do que aquelas com que podemos atualmente contar, e tenha daí resumido ou copiado algumas porções especificamente relacionadas com um daqueles (ou com ambos aqueles) reinados, permitindo-nos deste modo perceber um pouco melhor que episódios fariam parte do texto original da crónica quatrocentista.

Como parecerá evidente, o estudo da receção da Crónica de 1419 é passível de ser feito a partir de diferentes materiais. Os próprios apógrafos subsistentes são já um elemento dessa receção (e veja-se o interesse, deste ponto de vista, das considerações do copista/compilador de Pf, acima citadas, sobre a antiguidade e a linguagem dessa Crónica). Constrangimentos de vária espécie levaram-me, porém, a concentrar-me no aproveitamento da Crónica de 1419 por parte de historiógrafos portugueses e espanhóis dos séculos XV e XVI. Ser-me-ia de todo impossível, e de antemão o sabia, uma análise exaustiva dos materiais existentes. Nos séculos XV e XVI, a produção historiográfica portuguesa e castelhana aumentou exponencialmente; no caso português, grande parte da produção quinhentista permanece inédita até hoje e não é, por isso, tida em conta por parte da investigação, que normalmente se limita à historiografia ultramarina ou religiosa, ou às Crónicas de Duarte Galvão e de Rui de Pina e aos Sumários de 
Cristóvão Rodrigues Acenheiro (ou seja, às obras que vieram a ser editadas). Um caso expressivo é o dos Sumários de Crónicas, que Acenheiro não foi o único a redigir e conheceram, até, uma importante difusão ao longo do século XVI.

O carácter provisório de várias das conclusões a que cheguei será, pois, inevitável. Mesmo assim, os resultados obtidos ultrapassaram as expetativas iniciais. Para além da Crónica Breve do Arquivo Nacional, das Crónicas de Duarte Galvão e de Rui de Pina e dos Sumários de Rodrigues Acenheiro, obras que já se sabia terem aproveitado a Crónica de 1419 (mas cujo tipo de aproveitamento estava, em boa medida, por analisar), foram identificados outros textos dos séculos XV e XVI entre cujas fontes esteve a Crónica de 1419. Procurei, para todos estes textos, i) demonstrar o uso da Crónica de 1419 (exceto no caso dos textos primeiro mencionados, onde tal era desnecessário); ii) entroncar o códice da Crónica de 1419 manejado pelo redator do texto em causa no estema desta crónica atualmente passível de construção; iii) analisar a forma como cada um desses textos usou a Crónica de 1419; d) tecer, com base nestas premissas, considerações acerca do trajeto de cópias da Crónica da 1419 e/ou do conteúdo das suas partes não preservadas por nenhum dos apógrafos conhecidos.

De entre os textos analisados, um dos mais interessantes será o prolongamento da História de Portugal específico do ms. da Crónica Geral de Espanha que pertenceu ao Condestável D. Pedro e foi certamente por ele encomendado. A análise desta continuação mostra, com efeito, que os círculos do Condestável tiveram acesso quer às três crónicas seguramente da autoria de Fernão Lopes, quer à Crónica de 1419, de onde resumiram o reinado de D. Afonso IV e tiraram algumas informações sobre os de D. Afonso III e D. Dinis. A concordância do relato da morte de Inês de Castro presente nesta continuação com o de outros autores que sabemos terem conhecido a Crónica de 1419 (Pina e Acenheiro), em conjugação com a constatação anterior, praticamente assegura que o texto original da Crónica de 1419 incluía o relato da morte da Castro. Outro caso particularmente interessante é o de Gaspar Correia, que, na década de 30 do século XVI, quando estava na Índia, organizou uma compilação de crónicas. Por não ter tido acesso á Crónica de D. Sancho II da autoria de Rui de Pina, Correia socorreu-se de um exemplar da Crónica de 1419 para relatar esse reinado, transcrevendo ainda parte do capítulo inicial desta crónica dedicado ao reinado de D. Afonso III. Isto confirma a existência de cópias parciais das Crónicas de Rui de Pina dedicadas aos reis da primeira 
dinastia (todas as restantes cinco crónicas foram copiadas por Correia) e assegura que pelo menos uma cópia da Crónica de 1419 chegou a circular pelos domínios portugueses da Índia.

Os redatores de todos os textos quinhentistas que se socorreram da Crónica de 1419 parecem, por outro lado, ter aproveitado manuscritos cujo texto estava mais próximo de $\mathrm{P}$ do que de $\mathrm{C}$ (nenhum deles conheceu o próprio $\mathrm{C}$, e $\mathrm{P}$ é materialmente posterior a todos esses textos). Os principais meios difusores da Crónica de 1419 parecem ter sido a corte e o mosteiro de Santa Cruz de Coimbra.

\section{COMO CITAR ESTE ARTIGO}

\section{Referência electrónica:}

MOREIRA Filipe Alves - “A «Crónica de Portugal de 1419»: fontes, estratégias e posteridade. Tese de Doutoramento em Literaturas e Culturas Românicas apresentada à Faculdade de Letras da Universidade do Porto, Janeiro 2011. Orientação do Professor Doutor José Carlos Ribeiro Miranda”. Medievalista [Em linha]. №13, (Janeiro - Junho 2013). [Consultado dd.mm.aaaa]. Disponível em http://www2.fcsh.unl.pt/iem/medievalista/MEDIEVALISTA13/moreira1310.html

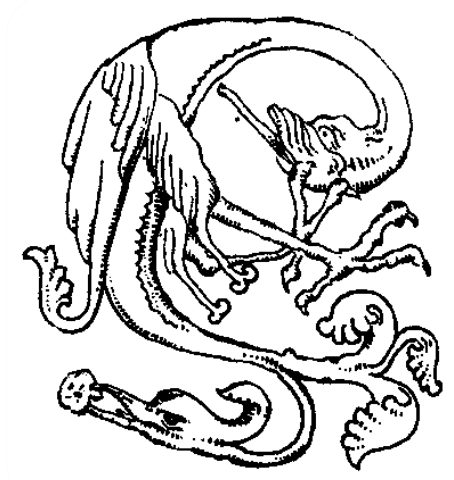

